Association for Information Systems

AIS Electronic Library (AISeL)

ICEB 2004 Proceedings

International Conference on Electronic Business

(ICEB)

Winter 12-5-2004

\title{
A Practical Approach to Credit Scoring
}

Jae H. Min

Youngchan Lee

Follow this and additional works at: https://aisel.aisnet.org/iceb2004

This material is brought to you by the International Conference on Electronic Business (ICEB) at AIS Electronic Library (AISeL). It has been accepted for inclusion in ICEB 2004 Proceedings by an authorized administrator of AIS Electronic Library (AISeL). For more information, please contact elibrary@aisnet.org. 


\title{
A Practical Approach to Credit Scoring
}

\author{
Jae H. Min ${ }^{1}$, Youngchan Lee ${ }^{2}$ \\ ${ }^{1}$ College of Business Administration, Sogang University, Seoul, 121-742, Korea \\ ${ }^{2}$ College of Commerce and Economics, Dongguk University, Gyeongju, 780-714, Korea \\ ${ }^{1}$ jaemin@ccs.sogang.ac.kr, ${ }^{2}$ chanlee@ mail.dongguk.ac.kr
}

\begin{abstract}
This paper proposes a DEA-based approach to credit scoring. Compared with conventional models such as multiple discriminant analysis, logistic regression analysis, and neural networks for business failure prediction, which require extra a priori information, this new approach solely requires ex-post information to calculate credit scores. For the empirical evidence, this methodology was applied to current financial data of external audited 1061 manufacturing firms comprising the credit portfolio of one of the largest credit guarantee organizations in Korea. Using financial ratios, the methodology could synthesize a firm's overall performance into a single financial credibility score. The empirical results were also validated by supporting analyses (regression analysis and discriminant analysis) and by testing the model's discriminatory power using actual bankruptcy cases of 103 firms. In addition, we propose a practical credit rating method using the predicted DEA scores.
\end{abstract}

Keywords: Credit scoring, Credit rating, Data envelopment analysis, Financial performance

\section{INTRODUCTION}

Credit scoring problems are basically in the scope of classification agenda (Anderson, 1984; Chen and Huang, 2003; Dillion and Goldstein, 1984; Hand, 1981; Johnson and Wichern 1998; Lee et al., 2002; Morrison, 1990; West, 2000) that is a commonly encountered decision making task in businesses, and it is a typical classification problem to categorize an object into one of predefined groups or classed based on a number of observed attributes related to that object (Zhang, 2000).

So far, a variety of methods such as linear probability and multivariate conditional probability models, the recursive partitioning algorithm, artificial intelligence approaches, multi-criteria decision-making (MCDM), mathematical programming approaches have been proposed to support the credit decision (Bryant, 1997; Buta, 1994; Coakley and Brown, 2000; Davis et al., 1992; Dimitras et al., 1996, 1999; Emel et al., 2003; Falbo, 1991; Frydman et al., 1985; Martin, 1997; Reichert et al., 1983; Roy, 1991; Tam and Kiang, 1992; Troutt et al., 1996; Zopounidis and Doumpos, 1998).

Offering financial institutions a means for evaluating the risk of their credit portfolio in a timely manner, such models can provide an important body of information to help them formulate their respective risk management strategies. In fact, banking authorities such as Bank of International Settlements (BIS), the World Bank, the IMF, and the Federal Reserve all encourage commercial banks to develop internal models to better quantify financial risks. ${ }^{1}$

1 The Basel Committee on Banking Supervision (1999), English and Nelson (1998), the Federal Reserve System Task Force on Internal Credit Risk Models (1998), Lopez and Saidenberg (2000), and Treacy and Carey (2000) represent some recent documents addressing these issues.
The purpose of this paper is to suggest a new approach to credit scoring, which is based on DEA. As opposed to well-known methods such as multiple discriminant analysis, logistic regression analysis, and neural networks, which require ex ante information of "good/bad" classification, this approach only needs ex post information of the observed set of input and output data of the objects of interest (client firms) to calculate their respective credit scores With these scores, we also provide a practical credit rating methods to classify client firms into several balanced classes.

\section{LITERATURE REVIEW}

In the credit industry, neural networks (NN) has recently been claimed to be an accurate tool for credit analysis among others (Desai et al., 1996; Malhotra and Malhotra, 2002; West, 2000). Desai et al. (1996) have explored the abilities of $\mathrm{NN}$ and the traditional statistical techniques such as linear discriminant analysis (LDA) and logistic regression analysis (LRA) in constructing credit scoring models. They claimed that NN shows a promise if the performance measure is the percentage of bad loans accurately classified. However, if the performance measure is the percentage of good and bad loans accurately classified, LRA is as good as NN. The percentage of bad loans correctly classified is an important performance measure for credit scoring models since the cost of granting a loan to a defaulter is much larger than that of rejecting a good applicant (Desai et al., 1996).

West (2000) has also investigated the accuracy of quantitative models commonly used by the credit industry. The results indicated that NN could improve the credit scoring accuracy. He also suggested that LRA is a good alternative to NN while LDA, k-nearest neighbor (k-NN), and CART (classification and 
regression tree) did not produce encouraging results. Commonly considered as a black-box technique without logic or rule-based explanations for the input-output approximation, the main shortcoming of applying $\mathrm{NN}$ to credit scoring lies in the difficulty of explaining the underlying principle for the decision to rejected applications (West, 2000).

Although NN and other traditional methods for credit scoring require ex ante information for business failure prediction, it is more useful in practice to build a credit scoring model based on ex post financial information. The idea is to develop a meaningful "peer group analysis" with specific financial characteristics that distinguish between two or more groups, and in the late 1990s, data envelopment analysis (DEA) was introduced to this peer group analysis for business failure prediction (Troutt et al., 1996; Simak, 1999; Cielen and Vanhoof, 1999).

As opposed to broadly known MDA, LRA, NN approach, DEA requires solely ex-post information, i.e. the observed set of input and output data, to calculate the credit scores. Yeh (1996) was one of the pioneers to combine DEA with financial ratio analysis. She utilized DEA to evaluate bank performance. Her study empirically demonstrated that DEA, in conjunction with financial ratio analysis, can effectively aggregate and reclassify perplexing ratios into meaningful financial dimensions, which enable analysts to gain an insight into the operating strategies of banks. Emel et al. (2003) proposed a credit scoring methodology based on DEA. Although their approach, which is applied to the limited number of Turkey's commercial banks, is not relatively delicate compared with conventional statistical analyses, it provides the base of this study.

DEA converts a multiplicity of input and output measures into a unit-free single performance index formed as a ratio of aggregated output to aggregated input. Conceptually, DEA compares the DMUs' observed outputs and inputs in order to identify the relative "best practices" for a chosen observation set. Based on these best observations, an efficient frontier is established, and the degrees of efficiency of other units with respect to the efficient frontier are measured. Therefore, in the context of credit scoring, the performance index via DEA measures the relative credit riskiness of the firms within credit portfolio (Emel et al., 2003). DEA, which computes a firm's efficiency by transforming inputs into outputs relative to its peers, may provide a fine mechanism for deriving appropriate categories for this purpose.

\section{RESEARCH METHODOLOGY}

The research methodology consists of seven steps, as outlined in Fig. 1. The first three steps deal with selection of firms for the study and with identification of indicators that may be used to evaluate the firms' financial performance. Step 4 uses DEA to obtain credibility scores of the firms. Step 5 validates the DEA-based credibility scores by comparing them against those obtained via regression and discriminant analyses, and by using actual bankruptcy cases. Finally, Step 6 proposes a credit rating method by investigating the distribution of good/bad firms' credibility scores.

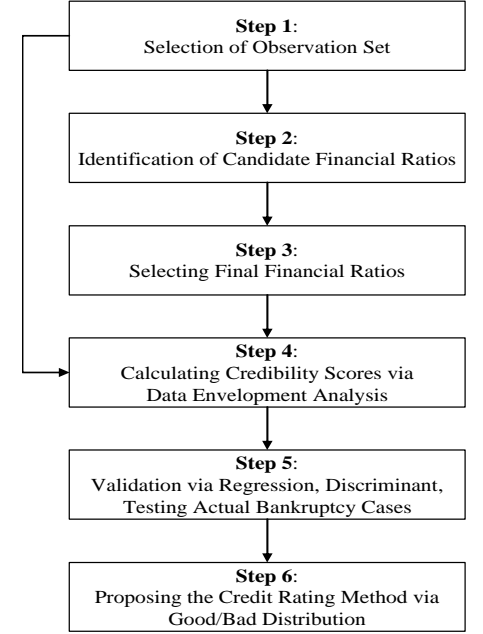

Fig. 1. Flowchart of the research methodology

Step 1: Selection of observation set. We select the firms applying for new credit allocation or whose credit limits are already allocated by the credit authority. At this stage, a certain degree of "homogeneity" in terms of industrial difference and scale-size is ensured among the firms. In this paper, we select only external audited manufacturing firms as a sample in order to satisfy this property.

Step 2: Identification of candidate financial ratios. The most common dimensions considered in financial performance evaluation are growth, liquidity, activity, profitability, productivity, and cost structure aspects. In order to cover these dimensions, a broad set of financial ratios needs to be computed. Some ratios in this set, however, may be similar to each other in terms of underlying financial meanings or in terms of mathematical properties. To identify diverse and financially meaningful ratios in this model, the literature review as well as loan officers' experience-based insight was employed.

Step 3: Selecting final financial ratios. The final selection of financial indicators is based on the expert opinion as well as the statistical factor analysis. The resulting set of indicators contains the most relevant financial classification dimensions while recognizing the mathematical relationships among the ratios.

Step 4: Calculating credibility scores via data envelopment analysis. In DEA, physical or monetary magnitudes are typically used as the input/output set. However, to eliminate scale-size effects in this study, financial ratios were used instead. The resulting DEA score is a relative ratio of two combined linear ratios. Also, we took advantage of multi-criteria ranking 
feature of DEA, a feature based on selection of the relatively best practices within the observation set, and on the radial distance from the efficient frontier comprising these best practices (Charnes et al., 1978; Oral and Yolalan, 1990).

Step 5: Validation via regression, discriminant, and testing actual bankruptcy cases. The purpose of this step is to establish the extent to which DEA results coincide with those of regression analysis, discriminant analysis, and actual bankruptcy cases.

(a) Regression analysis (RA): In some cases, due to data anomalies, DEA may not sufficiently discriminate firms' efficiencies. Thus, there is a need to test the explanatory power of the indicator set used in DEA. Linear regression analysis is suggested as a test criterion. For this purpose, the DEA scores are taken as the dependent variable, while the financial ratios used in DEA are set to be the independent variables.

(b) Discriminant analysis (DA): DA is used to establish the extent to which DEA scores can be used to classify the sample firms into two groups: "good" firms and "bad" firms. DA is a statistical technique used to classify an observation into one of a priori established groupings dependent upon the observation's individual characteristics. DA attempts to derive the linear combination of characteristics which best discriminates between predefined groups. In this study, financial performance, as measured by DEA, is used as the qualitative (i.e. a priori grouping) variable. There are two performance groups: The good firms group and the bad firms group. The good firms group is defined as those observations with DEA scores over a specific value, whereas the bad firms group is defined as those observations with DEA scores below that value. As will be discussed later, the specific value was chosen by taking into account the distribution of DEA scores. The financial ratios are used as explanatory variables in DA. One can then generate a discriminant function, and calculate the hit ratio (the percentage of right classifications) that shows the degree to which DA validates the classification obtained via DEA.

(c) Testing actual bankruptcy cases: The consistency of the DEA results is also checked against testing actual bankruptcy firms. The objective is to see the usefulness of DEA scores as a risk management tool in practical viewpoint.

Step 6: Proposing the credit rating method via good/bad distribution. Commercial banks or other financial institutions are adopting various credit rating methods to manage the client firms' credit riskiness, most of which utilize the probability of default derived by the neural networks or logistic regression analysis. In practice, an ex post approach is more useful in order to diagnose the financial performance of client firms and to rate their credit status. In this study, we propose a practical credit rating method by investigating the distribution of the firms' credibility scores.

\section{EMPIRICAL ANALYSIS}

The DEA-based approach was applied to current financial data of external audited 1061 manufacturing firms comprising the credit portfolio of one of the largest credit guarantee organizations in Korea.

\subsection{The sample data}

At the beginning of the study, there were approximately 1400 firms for which data were available. In order to provide a certain degree of homogeneity among firms in the observation set, however, the outliers, i.e. those firms having several ratios that deviate significantly (more than two standard deviations) from the corresponding mean, were removed and the data for the remaining 1061 firms were used.

\subsection{Selection of financial ratios}

Commonly accepted financial dimensions such as growth, liquidity, activity, profitability, productivity, and cost structure aspects are considered as a guideline to identify candidate financial ratios. From the previous studies (Altman, 1968; Beaver, 1966; Dimitras et al., 1996; Eisenbeis, 1978; Emel et al. 2003; Falbo, 1991; Jensen, 1992; Lee et al. 1997; Lee et al., 1999; Martin, 1997; Peel et al., 1986), we first selected 57 financial ratios, of which 43 ratios were grouped under previously mentioned dimensions through factor analysis. The loan officers' experience-based knowledge was then used to select final financial ratios that represent a firm's multidimensional financial characteristics. Combining the credit department officers' expert knowledge, the literature survey, and the authors' best judgment, we selected the final set of 6 financial ratios, and classified them as input and output variables for DEA.

The inputs to be minimized are financial expenses to sales, current liabilities ratio and absolute value of 1fixed assets ratio, as defined in Table 1.

Table 1. Input variables for DEA

\begin{tabular}{|c|c|}
\hline Input variables & Formula \\
\hline $\begin{array}{c}\text { financial expenses to sales } \\
\text { (FE) }\end{array}$ & financial expenses $\div$ sales \\
\hline current liabilities ratio (CL) & $\begin{array}{c}\text { current liabilities } \div \text { owners' } \\
\text { equity }\end{array}$ \\
\hline $\mid 1$-fixed assets ratio| (ABS) & $\begin{array}{c}\mid 1 \text {-(fixed assets } \div \text { owners' } \\
\text { equity) } \mid\end{array}$ \\
\hline
\end{tabular}

First, the ratio of financial expenses to sales (FE) shows the ability of a firm to pay financial expenses, which indicates the credit worthiness of a firm. Second, current liabilities ratio $(\mathrm{CL})$ is a proportion of current liabilities to owners' equity. This ratio is an indicator to measure stability of a capital structure. If this ratio becomes 
higher, a capital structure and a financial liquidity are in unstable status. Third, the absolute value of " 1 minus fixed assets ratio" (ABS) shows that fixed assets of a client firm should balance its capital base. If banks finance fixed assets with liabilities, especially current liabilities (since fixed assets will not bring revenues to the bank, at least in the short run), the client will have problems in paying back the credit. This will also lead to cash flow problems for the bank. Hence, the ratio of fixed assets to capital base should be close to one. As this ratio moves away from unity (1) in either direction, it indicates an imbalance.

The outputs to be maximized are capital adequacy ratio, current ratio and interest coverage ratio, as defined in Table 2.

Table 2. Output variables for DEA

\begin{tabular}{|c|c|}
\hline Output variables & Formula \\
\hline \hline capital adequacy ratio (CA) & owners' equity $\div$ total assets \\
\hline current ratio (CR) & current assets $\div$ current liabilities \\
\hline interest coverage ratio (IC) & $\begin{array}{c}\text { (EBIT }+ \text { interest expenses) } \div \text { interest } \\
\text { expenses }\end{array}$ \\
\hline
\end{tabular}

First, the capital adequacy ratio (CA) is a proportion of owners' equity to total assets. This ratio is an indicator of the capital adequacy of the firm. The more a firm finances itself with its own resources (the higher this ratio is), the less risky it is evaluated by credit authorities. Second, the current ratio (CR) is an indicator of the client's liquidity. The more liquid the firm is, the easier it can pay its current obligations. Therefore, the higher this ratio is, the better liquidity position the firm is in. Third, the interest coverage ratio (IC) is an indicator that shows the ability of a firm to pay its interest expenses with operating income. Therefore, the higher this ratio is, the more profitable the firm is.

\subsection{Calculating financial credibility scores via DEA}

Setting FE, CL, and ABS as input variables while CA, $\mathrm{CR}$, and IC as output variables, we ran DEA algorithm and computed the financial performance (credibility) scores of the 1061 firms. The scores were calculated using input-oriented CCR model assuming constant returns to scale. In this application, DEA scores were given as percentage points. Hence, the range of scores in the original model, i.e. $0-1$, will be reported as 0-100.

The resulting DEA credibility scores vary between 13.04 and 100. Firms with DEA score of 100 are considered best firms and are said to fall on "efficient frontier." Fig. 2 shows the distribution of DEA scores for the 1061 sampled firms.

As seen in Fig. 2, there are 16 firms with DEA scores of 100. As the DEA score of a firm is lower than others, its financial performance is considered relatively worse than other firms in the observation set. It is thus considered to be closer to a probable bad risk in the context of loan extension process.

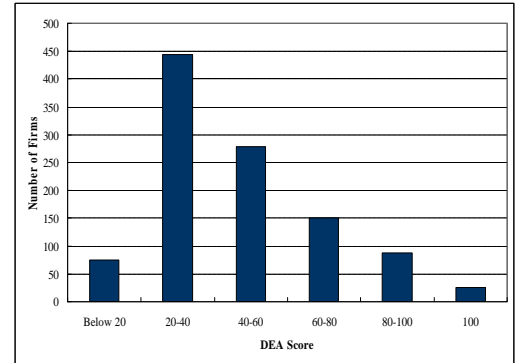

Fig. 2. Distribution of the DEA scores for the 1061 sampled firms

\subsection{Validating DEA scores}

(a) Regression analysis: In this context, DEA credibility score acts as the dependent variable while the six ratios are considered as the independent variables. To prevent overestimation, the regression was run excluding the "best observations" (firms with DEA score of 100).

Table 3. Regression analysis results

\begin{tabular}{|c|c|c|c|c|c|}
\hline \multicolumn{7}{|c|}{$\mathrm{R}^{2}=0.741 ; \mathrm{F}=491.803$ (Sig. $\left.=.000\right)$} \\
\hline & $\begin{array}{c}\text { Unstandardized } \\
\text { Coefficients }\end{array}$ & $\begin{array}{c}\text { Standard } \\
\text { Error }\end{array}$ & $\mathrm{t}$-value & $\mathrm{p}$-value & $\mathrm{VIF}$ \\
\hline \hline Constant & 72.94035 & 3.772205 & 19.33626 & 0.000 & \\
FE & -109.653 & 21.6798 & -5.05785 & 0.000 & 1.446 \\
CL & -50.8614 & 3.123891 & -16.2814 & 0.000 & 1.726 \\
ABS & -56.3548 & 3.039185 & -18.5427 & 0.000 & 1.411 \\
CA & 47.45822 & 4.30213 & 11.03133 & 0.000 & 1.790 \\
CR & 17.36333 & 1.085729 & 15.99233 & 0.000 & 1.273 \\
IC & 1.146138 & 0.184531 & 6.211091 & 0.000 & 1.324 \\
\hline
\end{tabular}

As shown in Table 3, all the variables have expected directions and are statistically significant, which tells us that the DEA algorithm successfully accounted for all six ratios at a statistically significant level.

Equation (1) represents the estimated regression relationship. This can be seen as a linear approximation of the DEA results. If the observation set is statistically large enough, the regression equation may also be used to evaluate a new credit applicant without having to run all the steps to derive its DEA score. In other words, by using Equation (1), it is possible to compute the linear approximation of its DEA score without having to run the DEA algorithm each time a new observation is added.

$D E A=73-109.7 F E-50.9 C L-56.4 A B S+47.5 C A+17.4 C R+1.2 I C$ Using the regression equation, we computed the "fitted DEA scores" and compared them with those obtained by DEA. As shown in Fig. 3, the actual DEA scores and the fitted scores do not differ significantly. The matched-pairs $t$ test also assured that there is no significant difference between the actual scores and the fitted ones $(\mathrm{t}$-value $=0.000, \mathrm{p}$-value $=1.000)$.

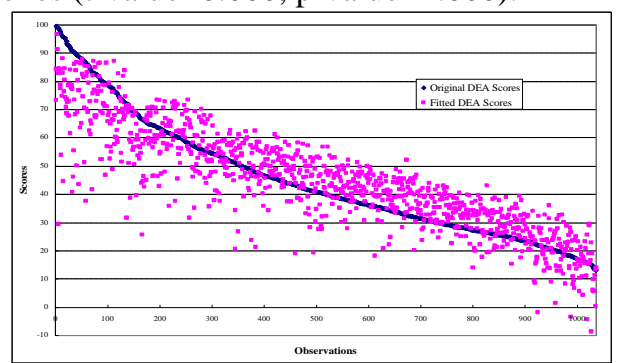

Fig. 3. Actual vs. fitted DEA scores 
(b) Discriminant analysis: An attempt was made to approximate the DEA results through DA. The firms were classified into two groups with respect to their DEA scores. The "cut-off" point between good and bad firms was selected in an ex post subjective manner, giving due consideration to the distribution of the DEA scores.

Table 4. Discriminant analysis result

\begin{tabular}{|c|c|c|c|c|}
\hline & \multicolumn{3}{|c|}{ Selected Group } \\
\hline & & Good & $\mathrm{Bad}$ & Total \\
\hline \multirow{3}{*}{$\begin{array}{l}\text { Predicted } \\
\text { Group }\end{array}$} & Good & $\begin{array}{c}440 \\
(84.9 \%)\end{array}$ & $\begin{array}{c}57 \\
(11.0 \%)\end{array}$ & 497 \\
\hline & $\mathrm{Bad}$ & $\begin{array}{c}78 \\
(15.1 \%)\end{array}$ & $\begin{array}{c}461 \\
(89.0 \%)\end{array}$ & 539 \\
\hline & Total & 518 & 518 & 1036 \\
\hline
\end{tabular}

In this study, median of DEA scores is selected as the cut-off point due to their skewed distribution. Thus, 518 firms were classified as good while the remaining ones were classified as bad. Next, DA was run with the above classification scheme as the category variable and the six ratios as the independent variables. The DA generated a discriminant function with five of the six ratios included (only IC being excluded). Table 4 showed that DA resulted in $(440+461) /(518+518)$ or $87.0 \%$ hit ratio.

Equation (2) represents the unstandardized canonical discriminant function:

$$
Z=-3.2+9.0 F E+4.4 C L+5.6 A B S-3.4 C A-1.5 C R
$$

As shown in Fig. 4, the DA-generated ranking did not differ significantly from that obtained by DEA, which is also statistically ensured by Spearman test (rank order correlation coefficient $=0.882$, $p$-value $=0.0001$ ). This tells us that the financial credibility scores derived by DEA can indeed be linearly approximated by DA, and provide useful information for business failure prediction.

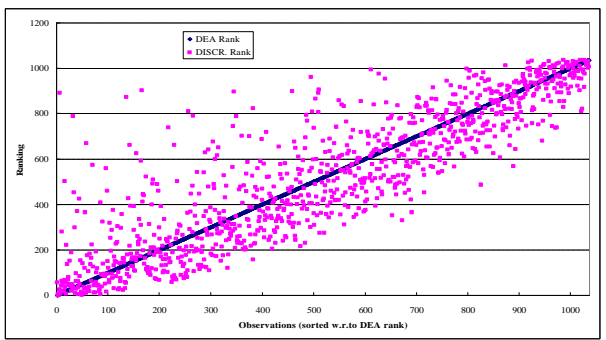

Fig. 4. DEA vs. DA rankings of sampled firms.

(c) Testing actual bankruptcy cases: We also checked consistency of the DEA results using actual bankruptcy cases of 103 firms. As shown in Table 5, the hit ratio of bankruptcy classification turned out to be $78.6 \%$. This result shows the usefulness of DEA-based methodology in financial distress prediction while DEA only considers ex post information of the firms.

Table 5. Classification result of actual bankruptcy firms

\begin{tabular}{|c|c|c|c|c|}
\hline \multicolumn{2}{|c|}{} & \multicolumn{3}{|c|}{ Predicted Group } \\
\cline { 3 - 5 } \multicolumn{2}{|c|}{} & Good & Bad & Total \\
\hline \hline $\begin{array}{l}\text { Actual } \\
\text { Group }\end{array}$ & Bad & $22(21.4 \%)$ & $81(78.6 \%)$ & 103 \\
\hline
\end{tabular}

\subsection{Credit rating method}

From a practical risk management point of view, the fitted DEA scores (via regression analysis) of credit applicant firms should be classified into several classes such as A, B, C, and so on. Table 6 shows the frequency distribution of good/bad firms' actual DEA scores with equal class intervals.

Table 6. Original frequency distribution of $\mathrm{good} / \mathrm{bad}$ firms

\begin{tabular}{|c|c|c|c|c|c|}
\hline Class & Good & Bad & Sum & $\%$ of Bad & $\%$ of Sum \\
\hline \hline Below 20 & 76 & 25 & 101 & $24.8 \%$ & $8.7 \%$ \\
\hline $20-40$ & 360 & 46 & 406 & $11.3 \%$ & $34.9 \%$ \\
\hline $40-60$ & 402 & 27 & 429 & $6.3 \%$ & $36.9 \%$ \\
\hline $60-80$ & 173 & 5 & 178 & $2.8 \%$ & $15.3 \%$ \\
\hline $80-100$ & 48 & 0 & 48 & $0.0 \%$ & $4.1 \%$ \\
\hline Upper 100 & 2 & 0 & 2 & $0.0 \%$ & $0.2 \%$ \\
\hline \hline Total & 1061 & 103 & 1164 & $8.8 \%$ & \multicolumn{2}{|c}{} \\
\hline
\end{tabular}

As one can see in Table 6 , the relative frequency of bad firms (\% of $\mathrm{Bad}$ ) decreases as the DEA scores increase. This means that the DEA score can serve as a very useful indicator to quantify the credit worthiness of the applicant firms, and thus banks or other financial institutions may grade the client firms' credit according to the DEA score classes. For example, a firm with DEA score ranged from 20 to 40 may be graded "E." However, the frequency of the firms in each DEA score class (\% of Sum) in Table 6 has a drawback in real world applications.

Table 7. Modified frequency distribution of $\mathrm{good} / \mathrm{bad}$ firms

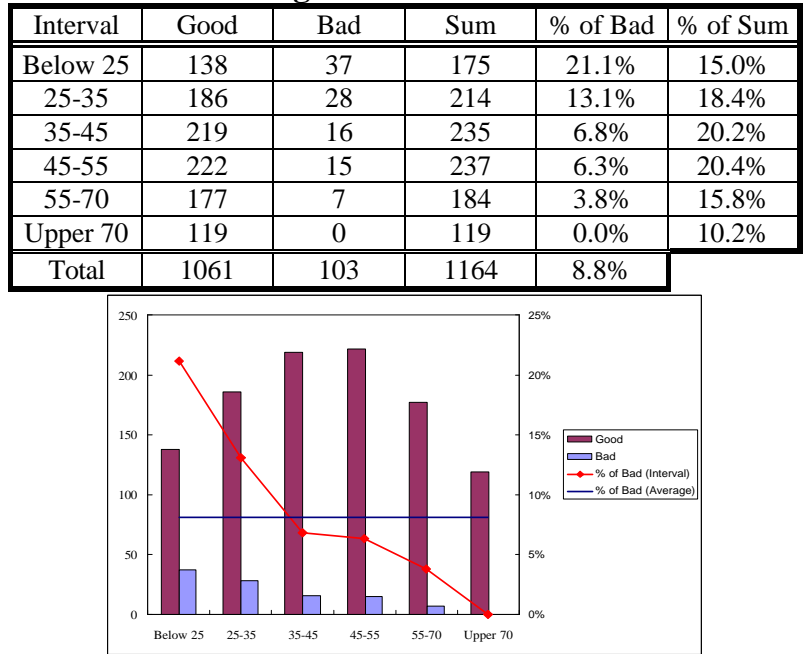

Fig. 6. Histogram of modified frequency distribution

Commercial banks or other financial institutions do not normally grade the client firms as shown in Table 6 due to their respective internal business policies. Table 6 shows the DEA score distribution (\% of Sum) is skewed to the right, which indicates that there are too many firms in low grades. This way of credit rating would not be practiced in real world applications. In general, commercial banks or other financial institutions want to grade the client firms according to the normal curve. ${ }^{2}$

\footnotetext{
2 According to the internal policies of financial institutions, their respective credit rating distributions may differ. In this study, however, we assume that the normal distribution is
} 
Fortunately, this problem may be solved through adjusting the class interval of DEA scores. Table 7 and Fig. 6 show the DEA score distribution of the client firms with modified class intervals.

As seen in Table 7 and Fig. 6, the modified distribution of the client firms guarantees that the bankruptcy ratio (\% of Bad) decreases as the DEA score increases, and the frequency of the firms in each class (\% of Sum) approximately follows the normal distribution.

\section{CONCLUSIONS}

This paper presents a new method of credit scoring using DEA. As opposed to broadly known multiple discriminant analysis, logistic regression analysis, and neural networks, DEA requires only ex post information to calculate credit scores. The discriminatory power of this method was also tested by comparing its results against those obtained by regression analysis and discriminant analysis, and by using actual bankruptcy cases. The empirical results suggest that this new approach can serve as a promising alternative for augmenting and/or replacing current credit scoring methods used by commercial banks and credit industry.

In terms of managerial implications, this method also gives a clear insight into how "bad" firms can improve their respective financial credibility. From the empirical results, it is shown that "good" firms have higher liquidity, lower bank loans, higher capital adequacy, and more balance between their equities and fixed assets. We also suggested a practical credit rating method using the estimated DEA scores derived by the method.

In addition, this new method ipso-facto allows the commercial banks or other financial institutions to monitor the exposures of their respective credit portfolios on an ongoing basis and to take preventive actions against the clients' defaults in an early stage.

\section{ACKNOWLEDGEMENT}

This work was supported by the Brain Korea 21 Project in 2004.

\section{REFERENCES}

[1] Altman, E.I., "Financial ratios, discriminant analysis and the prediction of corporate bankruptcy," The Journal of Finance, XXIII(4), pp589-609, 1968.

[2] Anderson, T.W., An Introduction to Multivariate Statistical Analysis, New York, NY: Wiley, 1984

[3] Basel Committee on Banking Supervision, Credit risk modeling: Current Practices and Applications, Basle: Basel Committee Publications, 1999.

[4] Beaver, W., "Financial ratios as predictors of failure," Journal of Accounting Research, pp71-102, Apr. 1966

[5] Bryant, S.M., "A Case-based Reasoning Approach to Bankruptcy Prediction Modeling," International Journal of Intelligent Systems in Accounting, Finance and Management, Vol. 6, No. 3, pp195-214, 1997.

[6] Buta, P., "Mining for Financial Knowledge with CBR," AI Expert, Vol. 9, No. 2, pp34-41, 1994.

[7] Charnes, A., W.W. Cooper, E. Rhodes, "Measuring the efficiency of decision making units," European Journal of Operational Research, Vol. 2, pp429-444, 1978. [8] Chen, M.C., S.H. Huang, "Credit Scoring and Rejected Instances Reassigning through Evolutionary Computation Techniques," Expert Systems with Applications,

adequate for the demonstration purpose.
Vol. 24, pp433-441, 2003.

[9] Cielen, A., K. Vanhoof, Bankruptcy prediction using a data envelopment analysis, Manuscript, Limburg University, Diebenpeek, 1999.

[10] Coakley, J.R., C.E. Brown, C.E., "Artificial Neural Networks in Accounting and Finance: Modeling Issues," International Journal of Intelligent Systems in Accounting, Finance and Management, Vol. 9, No. 2, pp119-144, 2000

[11] Davis R.H., D.B. Edelman,, A.J. Gammerman, "Machine Learning Algorithms for Credit-Card Applications," IMA Journal of Mathematics Applied in Business and Industry, Vol. 4, pp43-51, 1992.

[12] Desai, V.S., J.N. Conway, G.A. Overstreet Jr., "Credit Scoring Models in the Credit Union Environment Using Neural Networks and Genetic Algorithms," IMA Journal of Mathematics Applied in Business and Industry, Vol. 8, pp324-346, 1997.

[13] Desai, V.S., J.N. Crook, G.A. Overstreet Jr., "A Comparison of Neural Networks and Linear Scoring Models in the Credit Union Environment," European Journal of Operational Research, Vol. 95, pp24-37, 1996.

[14] Dillon, W.R., M. Goldstein, Multivariate Analysis Methods and Applications, New York: Wiley, 1984

[15] Dimitras, A.I., R. Slowinski, R. Susmaga, C. Zopounidis, "Business failure prediction using rough sets," European Journal of Operational Research, Vol. 17, No. 3, pp263-280, 1999.

[16] Dimitras, A.I., S.H. Zanakis, C. Zopounidis, C., "A Survey of Business Failure with an Emphasis on Prediction Methods and Industrial Applications," European Journal of Operational Research, Vol. 90, No. 3, pp487-513, 1996.

[17] Eisenbeis, R.A., "Problems in applying discriminant analysis in credit scoring models," Journal of Banking and Finance, Vol. 2, pp205-219, 1978.

[18] Emel, A.B., M. Oral, A. Reisman, R. Yolalan, "A Credit Scoring Approach for the Commercial Banking Sector," Socio-Economic Planning Sciences, Vol. 27, pp103-123, 2003.

[19] English, W.B., W.R. Nelson, Bank risk rating of business loans, Board of Governors of the Federal Reserve System Finance and Economics Discussion Series, November, 1998

[20] Falbo, P., "Credit Scoring by Enlarged Discriminant Analysis," OMEGA, Vol 19, No. 4, pp275-289, 1991

[21] Federal Reserve System Task Force on Internal Credit Risk Models, Credit risk models at major US banking institutions: current state of the art and implications for assessments of capital adequacy, Federal Reserve Bank Board of Governors, Supervisory Staff Reports, Washington, 1998.

[22] Frydman H.E., E.I. Altman, D. Kao, "Introducing Recursive Partitioning for Financial Classification: the case of Financial Distress," Journal of Finance, Vol. 40, No. 1, pp269-291, 1985.

[23] Hand, D.J. Discrimination and Classification, New York, NY: Wiley, 1981

[24] Jensen, H.L., "Using Neural Networks for Credit Scoring," Managerial Finance, Vol. 18, pp15-26, 1992.

[25] Johnson, R.A., D.W. Wichern, Applied Multivariate Statistical Analysis (Fourth Edition), Upper Saddle River, NJ: Prentice-Hall, 1998.

[26] Lee, G., T.K. Sung, N. Chang, N., "Dynamics of Modeling in Data Mining: Interpretive Approach to Bankruptcy Prediction," Journal of Management Information Systems, Vol. 16, pp63-85, 1999.

[27] Lee, H., H. Jo, I. Han, I., "Bankruptcy Prediction Using Case-based Reasoning, Neural Networks, and Discriminant Analysis," Expert Systems With Applications, Vol. 13, pp97-108, 1997.

[28] Lee, T.S., C.C. Chiu, C.J. Lu, I.F. Chen, "Credit Scoring Using Hybrid Neural Discriminant Technique," Expert Systems with Applications, Vol. 23, pp245-254, 2002 [29] Lopez, J.A., M.R. Saidenberg, "Evaluating credit risk models," The Journal of Banking and Finance, Vol. 24, No. 1-2, pp151-65, 2000.

[30] Malhotra, R., D.K. Malhotra, D.K., "Differentiating Between Good Credits and Bad Credits Using Neuro-fuzzy Systems," European Journal of Operational Research, Vol. 136, No. 2, pp190-211, 2002.

[31] Martin, D., "Early Warning of Bank Failure: A Logit Regression Approach," Journal of Banking and Finance, Vol. 1, pp249-276, 1997.

[32] Morrison, D.F., Multivariate Statistical Methods, New York, NY: McGrawHill, 1990.

[33] Oral, M., R. Yolalan, "An empirical study on measuring operating efficiency and profitability of bank branches," European Journal of Operational Research, Vol 46, pp282-294, 1990

[34] Peel, M.J., D.A. Peel, P.F. Pope, "Predicting corporate failure-some results for the UK corporate sector," Omega, Vol. 14, No. 1, pp5-12, 1986.

[35] Reichert, A.K., C.C. Cho, G.M. Wagner, "An Examination of the Conceptual Issues Involved in Developing Credit-Scoring Models," Journal of Business and Economic Statistics, Vol. 1, pp101-114, 1983.

[36] Roy, B., "The outranking approach and the foundations of ELECTRE methods," Theory and Decision, Vol. 31, pp49-73, 1991.

[37] Simak, P.C., DEA based analysis of corporate failure, Manuscript, University of Toronto, Toronto, 1999.

[38] Tam, K.Y, M.Y. Kiang, "Managerial Applications of Neural Networks: the Case of Bank Failure Predictions," Management Science, Vol. 38, No. 7, pp926-947, 1992.

[39] Treacy, W.F., M. Carey, "Credit risk rating at large US banks," The Journal of Banking and Finance, Vol. 24, No. 1-2, pp167-201, 2000.

[40] Troutt, M.D., A. Rai, A. Zhang, "The potential use of DEA for credit applicant acceptance systems," Computers and Operations Research, Vol. 23, No. 4, pp405-408, 1996.

[41] West, D., "Neural Network Credit Scoring Models," Computers \& Operations Research, Vol. 27, pp1131-1152, 2000.

[42] Yeh, Q.J., "The application of data envelopment analysis in conjunction with financial ratios for bank performance evaluation," Journal of the Operational Research Society, Vol. 47, pp980-988, 1996.

[43] Zhang, G.P., "Neural Networks for Classification: A Survey," IEEE Transactions on Systems, Man, and Cybernetics-Part C: Applications and Reviews, Vol. 30, No. 4, pp451-462, 2000 .

[44] Zopounidis, C., M. Doumpos, "Developing a multicriteria decision support system for financial classification problems: the Finclas system," Optimization Methods and Software, Vol. 8, pp277-304, 1998. 